Part 2: Practices 


\section{George Lewis}

\section{What is noise (music) to you? Why do you make it?}

Come to think of it, looking back on the past 40 years or so, I certainly have made a lot of what many people would call "noise-just noise." In fact, I've often said that I want my music to be like the weather, a fractal, self-similar noise that both poses and responds to conditions. I've also been associated with a diverse range of noisy people from around the world-the Great Chain of Noisy Beings.

So why do I do it? First of all, of course anyone can make noise, and noisiness is actually expected from some of us. But your question, with its parenthetical invocation of "music," seems to imply some great division between noise and music, or maybe even a bit of a hierarchy that moves from music to sound, and finally to noise. Because of its supposed extreme transgression (as distinct from the mere ineffability of music), noise becomes the highest stage of sonic utterance, and therefore the most desirable.

Certainly, many conceptions of noise tend to embed desire. We want something from our noise-we don't want it to be just sound-and when people announce themselves as noisers, we want something from them too.

My experience of that desire dovetails with the connection between noise, improvisation, spontaneity, and nomadism. As Gilles Deleuze and Felix Guattari observe in A Thousand Plateaus, "[i]t is a vital concern of every State not only to vanquish nomadism but to control migrations and more generally, to establish a zone of rights over an entire 'exterior'. ... If it can help it, the State does not dissociate itself from a process of capture of flows of all kinds, populations, commodities or commerce, money or capital, etc." 
To these kinds of actants, tight control over the flow of noise is vital. In fact, for traditional authority, spontaneous action itself is noise. But in his 1999 book Culture on the Margins, historian Jon Cruz points out, the trickster function of noise as "sound out of order. It evades, eludes, spills out of, or flows over, the preferred channels-out of place, resistant to capture." In that sense, the pretense to control becomes exposed as quixotic; noise and noisers routinely overflow the banks of propriety, resisting and unleashing. People hear the sound and say, "no one told me it could be like that; I wonder what else they haven't told me." Or they say, "wow, that music is really different"; once they start down that road, thoughts inevitably turn to what else might need to be different.

So when we want change, in the memorable phrase of the rap group Public Enemy, we "bring the noise" - in Egypt, Tunisia, Montreal, or elsewhere. The improvised, spontaneous, seemingly leaderless nature of these and other protests reminds us of the primary remit of new music and new noises: to declare that change is possible.

And let's not forget all that freedom talk: noise symbolizes freedom, and noisers use noise to free themselves and others. Of course, noise symbolizes not the object, but the subject. Subalternity speaks in noisy cadences.

Sometimes we don't bring the noise ourselves, but eagerly await its arrival. Those who wait are hardly passive, but form part of the evershifting, self-organizing assemblage of noisy desire. If we stop making noise, other noisers become discouraged, and we can imagine that discouragement working to the advantage of entrenched interests whose primary remit is eliminating our consciousness of possibility.

So, as Michel Foucault put it in a late essay, "What Is Enlightenment?," we must "transform the critique conducted in the form of necessary limitation into a practical critique that takes the form of a possible crossing-over." Maybe a while back it was enough just to get the noises out, but nowadays I find that the really good noisers pay close attention 
to sonic ecology. Even though, early on, the sonic epoché ("letting sounds be themselves") worked as well for such budding artist-noisers as John Cage as Husserl's phenomenological one did for thinking about sound in time, not attending to the symbols of the local soundscape turns out to be a good way to fall behind the Darwinian curve-say, if you live in one of those 'hoods where you have to know when to hit the deck.

Also, as 21st-century people, we routinely encounter noise designed to throw us off the scent of change-what Anthony Braxton, writing his Tri-Axium Writings in Paris in the wake of Guy Debord, calls "spectaclediversion." So part of what I do as a noiser involves training people to differentiate the sounds that empower from those that hamper and misdirect.

I once wrote that early African American free jazz was characterized by contemporaneous reception as embodying a tripartite assemblage consisting of anger, noise, and failure. Everybody knows that failure is an orphan, but it occurs to me now that very little self-characterized art music confronts anger, perhaps because the artists are afraid to say what they might be angry about; we've allowed you extra resources and your own bourgeois playpen, so they tell us.

But a sonic practice that embraces noise too insouciantly runs the risk of succumbing to the regulative force of genre, and thereby losing its noisiness. The afterimage of past transgressions can still be useful in reaping art world rewards, but we want an experimental music that can own up to the consequences of its noise, that can face up, when needed, to the possibility that there really is something to be angry about. In that way, noise and the noisers who make it can evade capture and live to noise again. 
NOISE IN AND AS MUSIC 


\section{"We Need You To Play Some Music"}

Phil Julian

At some point in the late 1980s I began to take an interest in "Noise Music." Noise is obviously a broad, subjective term, but by way of a personal definition this was music that made deliberate use of sounds generally regarded as nonmusical. Anything unpleasant, awkward, or difficult to listen to, set within a traditional musical context: a record, a concert, and so on. The objectionable presented as entertainment.

The route to "Noise" for me was largely via 1960s and 70s heavy rock albums that could be found easily and cheaply in second-hand record shops. Commercially available Top 40 music in the late 1980s by and large lacked the visceral qualities inherent in a heavily amplified, guitar-based record.

What became key was looking for the extremes within these recordings: the strangest, fastest, slowest, loudest examples. It was not long before the most interesting parts of these records had nothing to do with the songs or the musicianship of the groups, but were instead things like the extended equipment demolitions and amp smashes that occasionally acted as a finale. Most of these were nothing more than over-the-top showmanship, but the sounds created via feedback and broken equipment became far more interesting to me than the half an hour of songs you had to wade through to get to them.

It was clear that what interested me was music that "overwhelms" the listener in some way, or more specifically that completely inhabits the space it is given. This does not necessarily have to be achieved via extremes of volume, but can come more via a physical "presence" to the sound.

Rock acts in the 1960s and 70s often made references in interviews and on record sleeve notes to other musicians who had been influential, and 
this often included avant-garde, jazz, academic, or classical musicians. This provided further spurs to investigation in the search for extreme sounds.

All of the records I discovered around this time acted as a set of permissions. Yes, you could have an album with just one song on it. You could play this loudly or that quietly within one piece of music. You could drag that furniture around, record it, and present it as you would a string quartet. It didn't take much excavation to realize you could do absolutely anything you wanted to with sound.

This is certainly where an important and clear distinction between music and sound became apparent to me. The most interesting of these avant/ experimental/whatever records were not concerned with traditional musicality at all, and many had apparently little or no interest in even representing a musical experience. They didn't use formal conventions like songs or obvious narrative structure to prop up the "funny noises." They seemingly stripped away the unnecessary to focus far more on audio-related sensations and phenomena not usually directly associated with music - chance, error, silence, noise, repetition, and stasis-forcing the ear to create its own apophenic patterns.

At some point in the early 1990s I started to make my own recordings. Preinternet, the initial inspiration came largely from cassettes and fanzine reports of various "junk noise” performers in Japan and elsewhere. Equipment could be minimal, self-built, and recycled; everyday objects along with salvaged electronics, microphones, and a half-working reel-to-reel tape machine were used to make much of the early material. The key component was not musical ability, access to expensive equipment, or even much of a technical grasp, but imagination. Having a restricted amount of equipment to work with requires much more in terms of creative thinking to achieve the desired results, but also (in hindsight) provides a focused framework.

At roughly the same time, laptop computers had started to be used in music production and for live performance. They were slow by modern standards, expensive, and unreliable, but in the right hands could generate 
fascinating sounds difficult to achieve using analog equipment. Toward the end of the 1990s, they began to appear more frequently as solo performance instruments. There was a strange, remote, austere quality to these live laptop performances that was intriguing to watch. Audience members and sound technicians in particular were often openly hostile toward performers, and, though now commonplace, there is still to this day a suspicion that a solo laptop performance is a cop-out or a cheat in some way. The title of this chapter, for example, comes from a particularly irate bar manager who felt the need to interrupt a live laptop performance mid-set to complain about the perceived lack of music I was producing. Sadly for her, I don't do requests.

Like most instruments, the computer is as complicated or as easy as one chooses to make it. A performer can certainly just hit the spacebar and play back something pre-recorded. But they can also use a computer to create live music in a completely non-prepared, improvised way. Unfortunately, both of these approaches look about the same to an audience: a person gazing at a small screen. This seemingly represents "poor ticket value" to an audience that still wants a rock and roll show or event of some kind-a common but perhaps slightly strange expectation from an experimental music event.

Noise, in theory, should be the ultimate arena for an "anything goes" mentality from audiences and performers alike. If the Punk ethos was "learn three chords and form a band," Noise effectively did away with chords and bands completely. By the time I was involved, Noise Music had been around long enough to develop stylistic moves and a feel of the "traditional" about it. The dynamics of live Noise events were often similar. The way the music was constructed and shaped had a tendency to follow certain quiet-toloud patterns. Computers were still viewed with suspicion by audience and performers alike, but the sounds coming from them also had certain elements that were identifiable as common currency. In a small way, Noise had started to develop a fingerprint like any other genre of music that has been around for long enough. The feeling that a certain "sameness" had crept into the genre actually became a useful thing on a personal level. Things that had not 
been considered before became interesting, like structure in terms of volume and duration. Performer position (out of view of the audience, sitting in the audience rather than onstage, starting and finishing at unexpected moments, not being present at the performance at all, anonymity, etc.) became relevant. Ultimately it was important that these where not overused as they had a danger of becoming "tricks" that an audience would get used to seeing or expect in some way. In the end, the most relevant thing personally was to avoid obvious sound palettes and keep the instrumentation as broad as possible. Not being a musician means that all sounds have a potential use, whether they are derived from traditional instruments or elsewhere.

Fortunately, some of these slightly overused moves in Noise seem to have given way recently to a freer approach, and a general feeling of "anything goes" has started to emerge again. Because the term means different things to different people, Noise as a scene or genre can only ever be fragmentary and constantly evolving, something that leaves it in a unique, fluid position. 


\section{Lasse Marhaug}

\section{What is noise (music) to you?}

Noise music is, simply said, a field of music in which elements that feature prominently in other styles of music - such as melody, rhythm, and tonal harmony-take a back seat. Noise music is about the sound itself, and how you structure that sound is what defines it as music.

\section{Why do you make it?}

Because I like it. I enjoy the sound of dense electronic overload, feedback, and distortion. I like how noise both offers a space to move around freely within, and a feeling that engulfs you. It pleases me both emotionally and intellectually. In performance noise is overwhelming and you can't get away from it. The music is often physical. You feel it. Noise offers freedom from the dictatorship of emotions found in traditional music. You get from it what you bring to it. 
NOISE IN AND AS MUSIC 